\title{
The Microbiome and Preterm Birth: A Change in Paradigm with Profound Implications for Pathophysiologic Concepts and Novel Therapeutic Strategies
}

\author{
Birte Staude, ${ }^{1}$ Frank Oehmke, ${ }^{2}$ Tina Lauer, ${ }^{1}$ \\ Judith Behnke $\mathbb{D}^{1},{ }^{1}$ Wolfgang Göpel, ${ }^{3}$ Michael Schloter, ${ }^{4}$ Holger Schulz, ${ }^{5,6}$ \\ Susanne Krauss-Etschmann, ${ }^{7,8}$ and Harald Ehrhardt ${ }^{1}{ }^{1}$ \\ ${ }^{1}$ Department of General Pediatrics and Neonatology, Justus-Liebig-University and Universities of Giessen and Marburg Lung Center \\ (UGMLC), Member of the German Lung Research Center (DZL), Feulgenstrasse 12, D-35392 Gießen, Germany \\ ${ }^{2}$ Department of Gynecology and Obstetrics, Justus-Liebig-University, Feulgenstrasse 12, D-35392 Gießen, Germany \\ ${ }^{3}$ Department of General Pediatrics, University Clinic of Schleswig-Holstein, Campus Lübeck, Lübeck, Germany \\ ${ }^{4}$ Research Unit for Comparative Microbiome Analysis, Helmholtz Zentrum München GmbH, Ingolstädter Landstr. 1, \\ D-85764 Neuherberg, Germany \\ ${ }^{5}$ Institute of Epidemiology, Helmholtz Zentrum München, German Research Center for Environmental Health, \\ Ingolstädter Landstr. 1, D-85764 Neuherberg, Germany \\ ${ }^{6}$ Comprehensive Pneumology Center Munich (CPC-M), Member of the German Center for Lung Research (DZL), \\ Max-Lebsche-Platz 31, D-81377 Munich, Germany \\ ${ }^{7}$ Research Center Borstel, Leibniz-Center for Medicine and Biosciences, Borstel, Germany, \\ Member of the German Center for Lung Research (DZL), Germany \\ ${ }^{8}$ Institute of Experimental Medicine, Christian-Albrechts-University of Kiel, Kiel, Germany
}

Correspondence should be addressed to Harald Ehrhardt; harald.ehrhardt@paediat.med.uni-giessen.de

Received 4 May 2018; Accepted 13 September 2018; Published 2 October 2018

Guest Editor: Aris Antsaklis

Copyright (C) 2018 Birte Staude et al. This is an open access article distributed under the Creative Commons Attribution License, which permits unrestricted use, distribution, and reproduction in any medium, provided the original work is properly cited.

\begin{abstract}
Preterm birth poses a global challenge with a continuously increasing disease burden during the last decades. Advances in understanding the etiopathogenesis did not lead to a reduction of prematurely born infants so far. A balanced development of the host microbiome in early life is key for the maturation of the immune system and many other physiological functions. With the tremendous progress in new diagnostic possibilities, the contribution of microbiota changes to preterm birth and the acute and long-term sequelae of prematurity have come into the research focus. This review summarizes the latest advances in the understanding of microbiomes in the amniotic cavity and the female lower genital tract and how changes in microbiota structures contribute to preterm delivery. The exhibition of these highly vulnerable infants to the hostile environment in the neonatal intensive care unit necessarily entails the rapid colonization with a nonbalanced microbiome in a situation where the organism is still very prone and at an early stage of development. The global research efforts to decipher pathologic changes will pave the way to new pre- and postnatal therapeutic concepts.
\end{abstract}

\section{Introduction}

Microbiomes comprise commensal, symbiotic, and pathogenic bacteria, fungi, and viruses, which form an ecological entity and interact with themselves and with their particular host. For a long time, it has been assumed that microbiota colonization is restricted to body surfaces like skin and the gastrointestinal tract. However, it became clear in the recent years that microorganisms reside in nearly every human tissue including the mammary glands, the ovaries, the uterus, and the placenta. Thus the human body is colonized by trillions of microbial inhabitants. They constitute a 
diverse and individually varying ecological community which in addition changes with age [1]. In line with this, the former theory that the amniotic cavity constitutes a sterile environment had to be abandoned. It became clear that the healthy maternofetal unit is colonized with microbes and that this is a prerequisite for immune maturation as well as metabolic and hormonal homeostasis. Fetal life and the first year of life are a life span which is critical for the development of a well-functioning immune system and maintenance of long-term health. For these reasons, negative early-life events pose a special risk to somatic and psychomotor development. Pathologic changes in microbiomes predispose or contribute to acute and chronic morbidities of every organ at any age. Furthermore, functional changes in microbiomes trigger infectious complications. In this review we present the latest insights into the structure and function of our microbiome and how pathologic changes contribute to preterm labor, premature birth, and the acute and long-term sequelae of prematurely born infants. Despite the fact that fungi and viruses are part of microbiomes, most research efforts so far clearly focused on bacterial diversity. Thus, other microbes than bacteria are mostly excluded in this review, simply because no data is available.

\section{Functional Traits of the Microbiome of the Lower Urogenital Tract and the Fetomaternal Unit}

The amniotic cavity has long been viewed as a sterile environment where the fetus is protected from the harmful external influences and threats. First reports emerged with the beginning of the new millennium, which questioned this hypothesis and described an intrauterine and placental microbial environment [2-4]. With the advancements in molecular techniques it became clear that the placenta, the amnion, and the fetus share large proportions of a common microbiome and that the maternal microbiome drives the development of the fetal immune system $[5,6]$. The placental microbiome, under physiologic conditions, harbors nonpathogenic commensals including Firmicutes, Tenericutes, Proteobacteria, Prevotella, Neisseria, Bacteroidetes, and Fusobacteria but also potential pathogenic species like Escherichia coli [7]. As its detection is based on molecular techniques, the scientific discussion is ongoing whether the placental microbiome contains viable microbiota or just microbial components. Nonetheless, a regulatory function is currently assumed [8].

The vaginal microbiome resembles that of the cervix and is physiologically dominated by Lactobacillales, but Clostridiales, Bacteroidales, and Actinomycetales are also regularly detected. Bacterial community differences and shifts are almost exclusively detected between different Lactobacillus strains without any negative impact on pregnancy outcomes. During pregnancy, microbial richness and diversity are reduced along with an increased bacterial load. At the same time, the prevalence of potential pathogens like microbial species of ureaplasma and mycoplasma is reduced. The taxonomic composition of the microbial community of the vagina remains stable during pregnancy with an increase of the microbial diversity before birth of the healthy infant at term. These data lead to the conclusion that the composition of the vaginal microbiota is tightly regulated during pregnancy and that the switch to the nonpregnant situation precedes and maybe even triggers birth [9-13].

Microbial diversity and orchestrated structural changes during early life are key features for a healthy microbiome. Ethnicity and regional differences have a key impact on the vaginal microbiota. It remains to be determined whether changes in the vaginal microbiome observed in Hispanic and black women account for the increased rate of preterm delivery in these ethnic groups [14-16].

The fetus swallows huge amounts of amniotic fluid. This explains why its gut gets colonized with the intrauterine microflora already before birth. After birth, the infant gets rapidly colonized by maternal vaginal, gut, and skin microbiota. In the term infant, the mode of delivery either by vaginal birth or by caesarian section determines microbial diversity and whether the gut is primarily colonized by the maternal vaginal and fecal or the skin microbiota. These data are a first scientific indication that early events have a long-term health impact on microbiota structures [17-20]. In contrast to the situation at term, the decision of preterm delivery by caesarian section or vaginal birth does not have an impact on gut microbial diversity and longitudinal microbiota changes and microbiota display a pattern distinct from that at term. As an example of the disparities, preterm microbiota lack Bacteroides species, which display a delayed colonization pattern after caesarian section. Although microbiomes are principally able to adapt to that of the term infant within several weeks, the intrauterine and postnatal miscolonization poses a major threat to the health of the preterm infant [21-23]. The following chapters summarize the substantial advances in our understanding of microbiota structures and dynamics during pregnancy and after birth.

\section{Pathologic Changes of the Microbiome Associated with Premature Labor and Preterm Delivery}

The reasons for preterm labor comprise a multitude of different causes including maternal psychosocial distress, hormonal changes, uterine overdistension, cervical disease, vascular and maternal disorders, and breakdown of the maternal-fetal tolerance [24]. Among these, infection and inflammation are the main drivers of preterm labor and account for at least one half of preterm births [24-26]. Till today, histopathology is the gold standard to determine chorioamnionitis in contrast to the low sensitivity and specificity of clinical evaluation scores and laboratory parameters [27]. In severe chorioamnionitis, a typical pattern with an increase in bacterial abundance and reduced diversity with the dominance of bacteria has been observed, which is not seen in the physiologic situation [28]. The evolutionary attenuation of the maternal and fetal immune system enables the intrauterine growth of the fetus, but immune tolerance of the mother at the same time puts the fetus at risk for infection [29]. The diagnosis of a maternal infection is of crucial importance, as the fetus, exposed to 
microbiota in the amniotic cavity, experiences an immunologic adaptation. This new phenomenon is termed the socalled immunotolerance or immunoparalysis. This means that the previous or ongoing exposure to microbiota suppresses the necessary physiologic immune response and that an adequate increase in classical markers of inflammation and infection is not guaranteed $[30,31]$. The placental microbiota structures display distinct patterns in term and preterm born infants, independent of the mode of delivery, and can be influenced by living conditions like excessive weight gain during pregnancy $[32,33]$. Microbial species of ureaplasma and mycoplasma but also Aerococcaceae, Bifidobacteriaceae, and Fusobacteria predominate or are even exclusively present in the membranes of preterm delivered babies. Conversely, bacterial dysbiosis and inflammation in the fetal membranes can occur without preterm labor and without the typical clinical signs and seems not to put the fetus at risk for preterm delivery $[2,4,34]$. In the situation of preterm labor, a shift of microbiota with reduced microbial diversity takes place. Latest molecular techniques proved superior to detect microbial invasion and diversity compared to conventional culture techniques, which opened a new diagnostic window of opportunity [35]. The long-prevailing concept of bacterial ascension or transmission from the urogenital tract as the main driver of chorioamnionitis and amniotic inflammation was based on the bacteriological detection of microbes typically present. They include bacterial species of the genera Streptococcus, E. coli, Gardnerella spp., Prevotella, Gonorrhea, Treponema, Chlamydia, Ureaplasma, and Mycoplasma as well as yeasts like Candida [13, 36-38]. Further species including anaerobic Fusobacteriaceae were recently detected by the non-cultivation-based techniques.

In fact, the microbiome gets dominated by abundance of bacteria from the urogenital tract, the gut, and the oral cavity (Figure 1). This shift is accompanied by alterations in microbial and metabolic pathways, which are suggested to contribute to preterm labor and birth [34, 39]. The lower urogenital tract and the perianal region constitute a microbial epitope which is highly influenced by the bacterial colonization of the gut and the local viability conditions. Microbiomes change during pregnancy, and differences in composition have long been acknowledged to account for variations in preterm birth rates $[11,16,40,41]$. The reduction of microbial richness and diversity and changes in microbiome structure seem to occur early, in the first to second trimester of pregnancy, and there seem to exist racial disparities $[14,42-44]$. That is, the cervical microbiota from women with Chlamydia trachomatis infection, which predisposes for preterm birth, differ completely from that of healthy women with respect to microbial diversity. They display a change in microbial taxa away from Lactobacillus species to anaerobes $[43,45]$. While Lactobacillus species that dominated cervical microbiota have a lower risk of invasion of the amniotic cavity and chorioamnionitis after premature rupture of membranes, the prevalence of Gardnerella and Sneathia increases the probability [46].

Microbiota from the oral cavity can equally induce chorioamnionitis, when they are translocated via the bloodstream or by sexual practices. Members of the genera
Streptococcus, Porphyromonas, Filifactor, Campylobacter, and Fusobacterium represent species which were repetitively connected with preterm labor. The scientific data point out that gut microbiota constitute the third source for bacterial translocation and can cause amniotic infection and chorioamnionitis. Reduction in microbial diversity and changes in gut microbiota occur during pregnancy with a dominance of Proteobacteria and Acinetobacteria away from Bifidobacterium, Streptococcus, Clostridiales, and Bacteroides, which predisposes for preterm delivery and disease [4751]. The pathologic changes in the amniotic microbiome are retrieved in meconium samples from preterm infants with a high accordance. Microbiota are shifted to strains of the genera Enterobacter, Enterococcus, Photorhabdus, and Tannerella, which are known for their inflammatory, and potentially preterm birth inducing, properties $[39,52,53]$. In line with these observations, the type of nutritional diet or an active inflammatory bowel disease impacts on the gut microbiota composition, and the risk of preterm delivery is increased in these patients. This underlines the concept that a change in maternal gut microbiota is one of the responsible triggers [54].

\section{The Consequences for the Premature Infant}

Inflammatory diseases represent the biggest threat to the preterm infant and affect all organs, including the immature lung, cardiovascular system, immune system, brain, eye, and gastrointestinal tract, with acute and persistent consequences for the patient's health. Infection accounts for or aggravates acute respiratory distress, leakage, and arterial hypotension after birth. Simultaneously, all organs are at high risk for secondary complications including NEC, nosocomial infection, cerebral damage, retinopathy of prematurity, and endocrinological nonbalance. Infection promotes the establishment of BPD and somatic and developmental disorders [55].

Antibiotic therapy is aimed at combating life-threatening pre- or postnatal infections with pathogenic microbiota, but they cannot reduce or prevent the concomitant inflammatory organ damage. So far, most pathomechanistic insights are available for the inflammatory damage to the immature lung and efficient therapeutic interventions are restricted to a very limited number of drugs. The reason for the so far unsuccessful establishment of effective therapeutic interventions is based on the complexity of the involved pathomechanisms. The complex interplay between different central pathways and persistent cell phenotype distortion after a one-time injury poses further obstacles that need to be bypassed to reach therapeutic efficiency [56-59]. The following sections are dedicated to the detailed description of some of the most important disease burdens provoked by microbial dysbiosis. They summarize the actual status of therapeutic interventions with proven efficacy. Special focus is drawn to highlight the impact of the disturbed endogenous gut microbiome (Figure 2).

\section{Microbiota of the Airways and Bronchopulmonary Dysplasia}

Bronchopulmonary dysplasia (BPD) is the chronic lung disease of the preterm infant leading to life-long limitations 


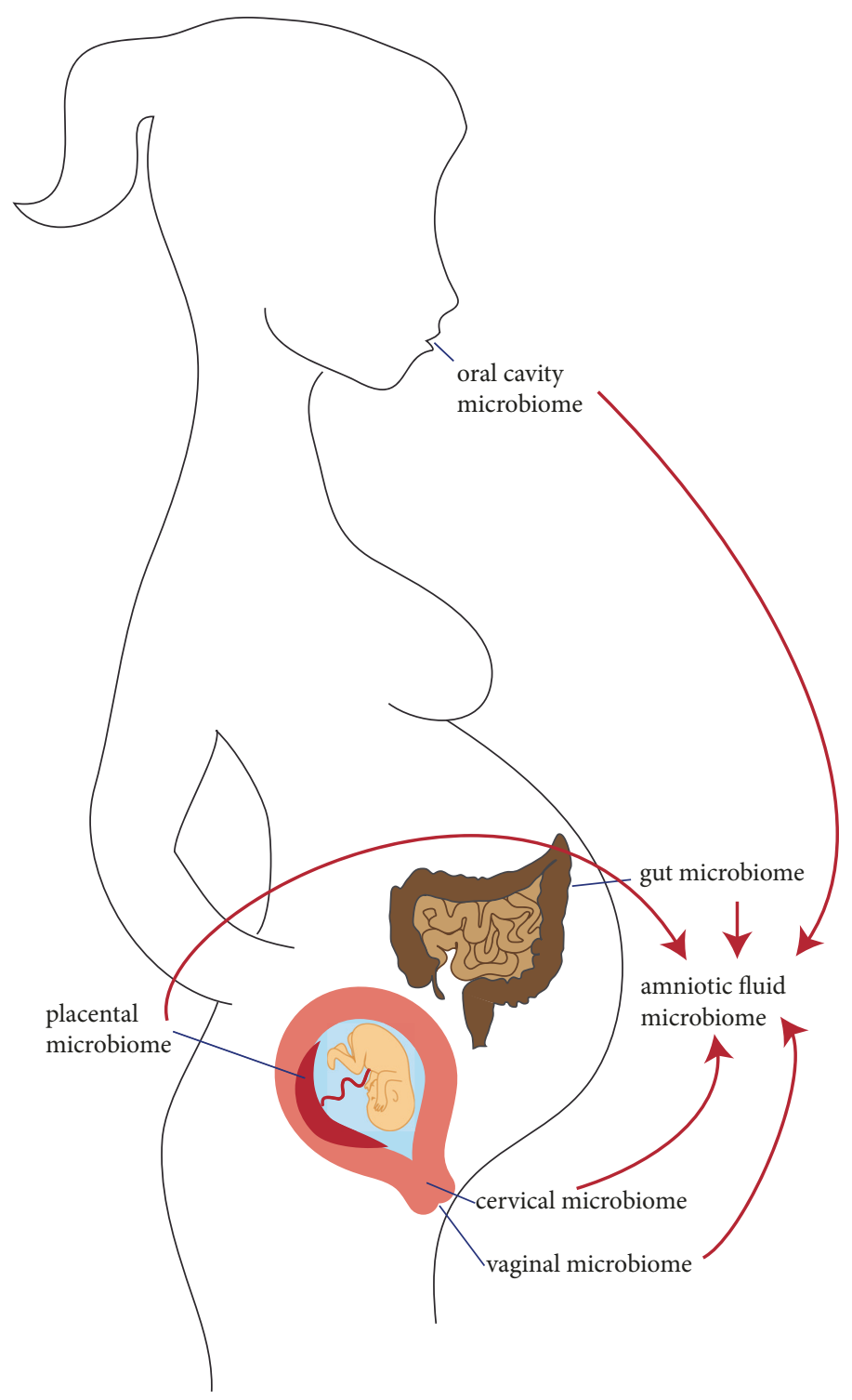

FIGURE 1: Origin of microbiota in the amniotic cavity leading to preterm birth: The microbiome in the amniotic cavity has long been thought to originate exclusively from the vaginal and cervical microbiome. But microbiota from the oral cavity, gut, and even the placenta provide a substantial contribution to the microbiome in the amniotic cavity mainly via haematogenic spread.

in lung function [59]. On a pathophysiologic level, BPD is characterized by distorted alveolar and vascular growth in the saccular stage of lung development. Central to the pathogenesis is the pulmonary inflammatory response after birth, which is mainly provoked by pre- and postnatal infections and the life-saving therapies of mechanical ventilation and oxygen supply [58]. While chorioamnionitis and special pathogens like bacterial species derived from ureaplasma are well acknowledged to contribute to the disease in animal trials and preterm cohort studies, the impact of microbial colonization of the respiratory tract in utero and after birth was neglected until recently [60-63]. This is surprising, considering the tremendous impact of the microbiome on other pulmonary diseases and immunity of the lung including asthma, pneumonia, cystic fibrosis, COPD, and even pulmonary fibrosis. The airway of the preterm infant is not sterile at birth and its microbiome is highly influenced by the microbiome of the amniotic fluid. Differences in colonization and clinical parameters allow the categorization into disease clusters, which are predictive for the clinical course and outcome [64]. Reduced microbial diversity at birth, initial abundance of ureaplasma species in tracheal aspirates of ventilated preterm infants, and more pronounced changes in the longitudinal microbial community are associated with higher severity of BPD. The association of a predominance of Proteobacteria and decrease in Lactobacillus species in 

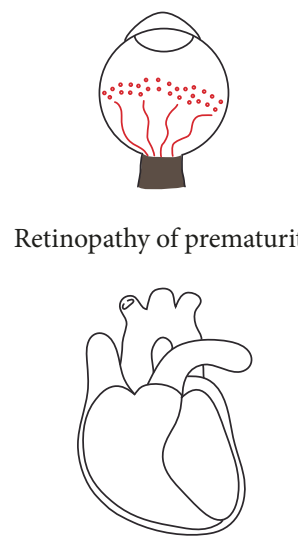

Cardiovascular compromise Pulmonary hypertension

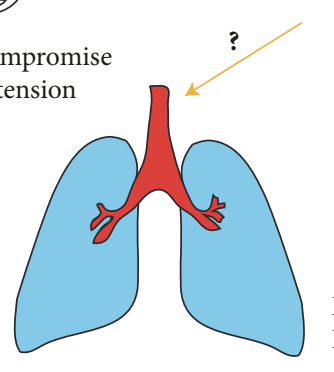

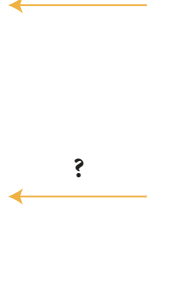

Respiratory distress

Bronchopulmonary dysplasia

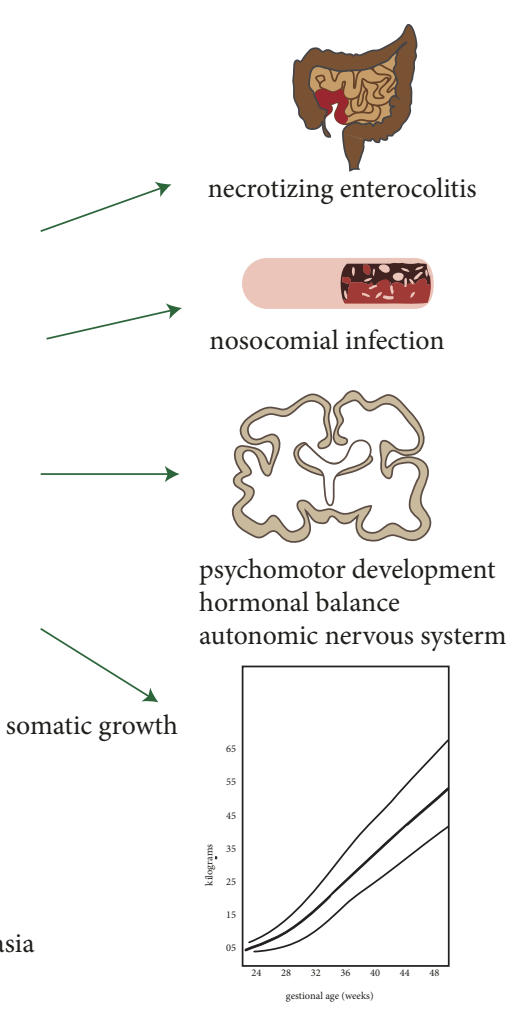

FIGURE 2: Impact of gut microbiota on the acute and long-term morbidities in the preterm infant: The gut microbiota exerts a central influence on human health. In the preterm infant, their impact on NEC and nosocomial infection is well recognized. First studies hint to an important impact on somatic growth, psychomotor development, autonomic regulation, and hormonal balance. In contrast, the contribution to the other acute and long-term sequelae remains to be determined.

the airways of infants with severe BPD was recapitulated in the murine animal model with major impact on the regulation of central lung signaling pathways [65-68]. The well-accepted further dimension arising from the interaction of gut microbiota with the lung in other pulmonary diseases termed the gut-lung axis needs to be established for BPD.

\section{The Significant Impact of Microbiota on Necrotizing Enterocolitis}

In contrast to $\mathrm{BPD}$, the important contribution of bacteria to the pathogenesis of necrotizing enterocolitis, which constitutes one of the most devastating morbidities of prematurity, is well established. NEC is considered to be a multifactorial disease. The inflammatory response of the gut to microorganisms is a central hypothesis of necrotizing enterocolitis pathogenesis $[69,70]$. The great beneficial advantages of breast milk provision are attributed to microbiota diversity and the shaping of immunologic properties [71]. In contrast, antibiotic therapy drives microbial dysbiosis and increases the risk of necrotizing enterocolitis [72]. Derived from these findings, the benefits of prophylactic application of probiotic strains of Bifidobacteria, Lactobacillus, and Saccharomyces was tested in varying experimental and clinical settings. Despite the heterogeneity of results and the need for large-scale meta-analyses, the most recent reviews clearly established a benefit of probiotics to nearly halve the risk of necrotizing enterocolitis and to reduce the incidence of nosocomial infection and death $[73,74]$.

Postnatally, the gut gets colonized by Gram-positive and Gram-negative bacteria mostly with a facultative or strictly anaerobic metabolism. In the term infant the gut is dominated by Bifidobacteriales and Bacteroides. In the preterm infant the presence of a large number of different genera including Anaerococcus, Aquabacterium, Bacillus, Bifidobacterium, Corynebacterium, Micrococcus, Oceanobacillus, Propionibacterium, Pseudomonas, Rothia, Sarcina, Sneathia, and Streptococcus has been described. As a general phenomenon, the gut microbiome of the preterm infant is dominated by Proteobacteria even when breast milk provision is assured and the appearance of Clostridium and Vellonella species is retarded [53, 75-78]. The microbiome is highly impacted by pre- and postnatal antibiotic therapy [79]. In this context, probiotic therapy aims to establish and maintain physiologic gut microbiota structures.

A strong dominance of Gram-negative bacteria and a decrease in anaerobic bacteria are described before onset of clinical symptoms of necrotizing enterocolitis, but whether altered microbial structures predispose for necrotizing enterocolitis or are a consequence of gastrointestinal or immunologic immaturity remains an open question. The 


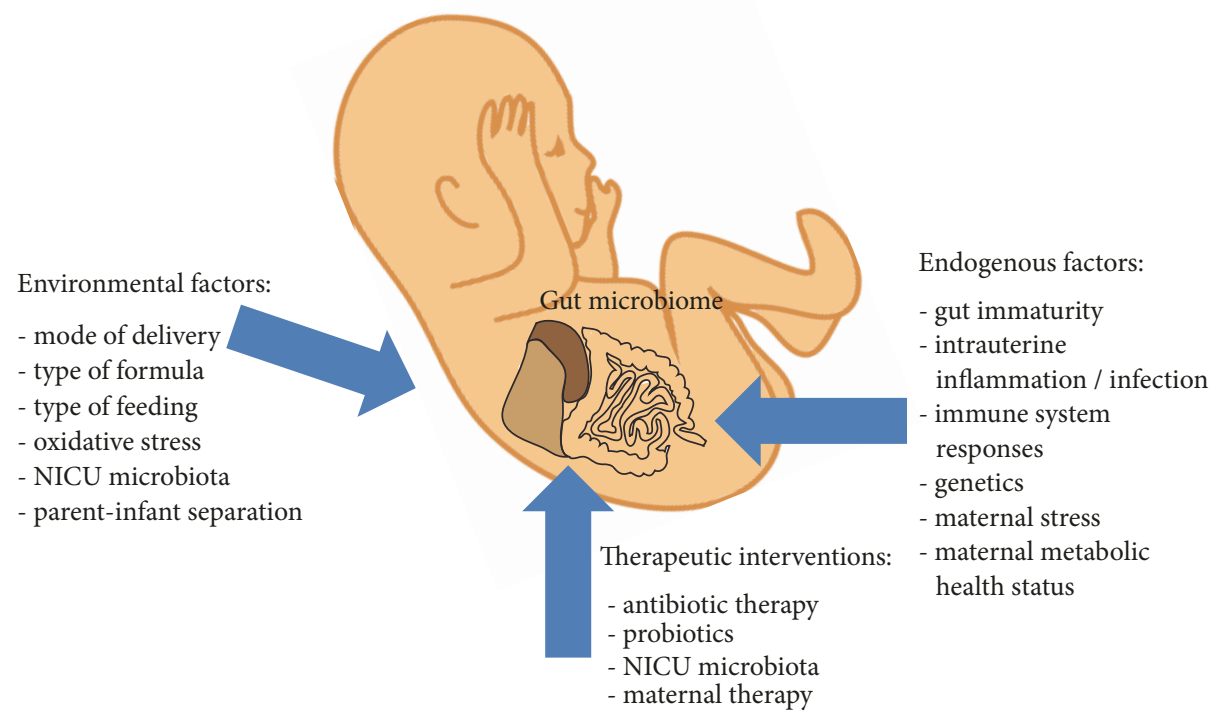

FIGURE 3: Factors determining the composition of gut microbiota in the preterm infant: The microbiome of the gastrointestinal tract of the preterm infant varies widely from that at term and is impacted by a plenty of endogenous and environmental factors and pre- and postnatal therapeutic interventions.

discrepancies in microbiome structures between the feces and samples obtained from the oral cavity or stomach and the impact of microbial dysbiosis of the upper gastrointestinal tract are awaiting further clarification. Presence of Gramnegative bacteria and staphylococci allows the conclusion of their acquisition from the NICU environment [80]. Microbial colonization can be separated into peripartal acquisition as described, i.e., for Escherichia coli and Candida albicans and hospital acquired microbial structures including Klebsiella, Enterobacter, and Acinetobacter species and Candida species other than Candida albicans [81]. Taken together, studies of the intestinal microbiome revealed a reduction of bacterial diversity and a shift of microbiota from Bacteroidetes and Firmicutes towards Proteobacteria and potentially pathogenic species including Staphylococcus aureus, Escherichia coli, Shigella spp., Citrobacter spp., and Klebsiella spp. before the onset of clinical symptoms of necrotizing enterocolitis [78, 82-85].

\section{Microbial Dysbiosis and the Risk for Nosocomial Infection}

Nosocomial infections pose a special risk to the premature infant. Due to the immaturity and immunologic incompetence of the immune system, the preterm infant is particularly vulnerable to nosocomial infections in the hostile environment of the neonatal intensive care unit $[30,31$, 86-90]. Furthermore, therapies with antenatal steroids and magnesium as well as small-for-gestational-age status and antenatal smoke exposure seem to further impact and diminish the immunologic response capacity [91-94]. Therefore, skin and gut microbiota colonization and maturation are important prerequisites to prevent pathogen overgrowth and nosocomial infection. The skin of the healthy term and preterm infant is dominated by Firmicutes, Actinobacteria, Proteobacteria, and Bacteroidetes exposing them to nosocomial infection $[95,96]$. The physiologic dominance of gut microbiota structures by Bifidobacteria may serve as a protective factor from gut-epithelial translocation. The differences in gut microbiota between preterm and term born infants at the onset of sepsis are used as an explanation for the vulnerability of the preterm infant and the important role of the gut microbiome in disease initiation. Concordance of microbiota isolated from the gut of infants with sepsis and bacteria identified in positive blood cultures supports this assumption [97-99]. The actual pathomechanistic understanding suggests the following sequence: The preterm infant is exposed to the hostile environment of the neonatal intensive care unit and gut microbiota display a big disparity after birth. A uniform microbiome is established within the first weeks of life with prevalence of highly pathogenic bacteria including Staphylococcus, Enterococcus, and several Enterobacteriaceae, while Bifidobacteria are infrequently detected. Reduction in microbial diversity with predominance of Staphylococci is again another feature predisposing for late-onset infection [100]. Not surprisingly, pre- or postnatal antibiotic therapy reduces microbial diversity and impedes the establishment of physiologic gut microbiota with a shift from Firmicutes and Bacteroidetes towards Proteobacteria and Actinobacteria [85, 101-103].

Taken together, the gut microbiome of the preterm infant is highly impacted by endogenous and environmental factors and maternal and postnatal therapeutic interventions which accounts for the high susceptibility for nosocomial infection (Figure 3). 


\section{The Gut-Brain Axis in Prematurity}

Brain development and function undergo fundamental steps in the last trimester and in the first year of life. The physiologic steps of brain folding and the developmental steps of the brain connectome far outreach the increase in brain volume and highly impact functionality. Their functional importance can be derived from preterm infants with severe limitations in brain functions, which display tremendous alterations in these critical steps $[104,105]$. More and more data from animal and human studies support the finding that the gut microbiome, especially at early postnatal stages, has tremendous impact on behavioral and stress responses later in life [106-110]. The term gut-brain axis summarizes not only the multiple and complex functions of the cerebrum, but endocrine homeostasis, the sympathetic-parasympathetic, and even the enteric nervous system. The neurologic disorders comprise diseases like autism spectrum disorders, depression, and anxiety which are frequently observed in former preterm infants and restrict their quality of life beyond intelligence and gross and fine motor functions $[111,112]$. Even persisting hormonal dysregulations in former preterms are coming into the focus of research [113]. Underlining the functional relevance of the gut-brain axis to the neurodevelopmental outcome after prematurity, higher and persisting prevalence of Bifidobacteria in the gut microbiome is associated with improved scores for mental development at 24 months [114]. Convincing animal data demonstrate the far-reaching impact of pre- and postnatal microbiota changes on brain development and the different functional regions which were reproduced in first association studies in children [115-117]. The gut-brain axis is not a one-way but the gut and the brain impact each other bidirectionally which can lead to multiplication in effect size [118-120]. This comes especially true as the preterm infant is exposed to high stress levels and repeated painful procedures [121]. Future studies will have to elucidate how microbiota modulate brain development and function physiologically compared to preterms, how these early life events lead to persisting psychomotor sequelae, and whether microglia cells are the only targets within the central nervous system [122]. Vice versa, it remains to be determined how impaired brain function impacts physiologic microbiota structures.

\section{Breast Milk and Beyond to Shape Physiologic Microbiota Structures}

Breast milk is the optimal nutrition of the preterm infant with respect to acute and long-term health, somatic growth, and psychomotor development. It is well established from studies in healthy newborn that the infant's microbiome is crucially promoted and shaped by the microbiota, antiinflammatory and antioxidative properties, growth factors, hormonally active substances, and cytokines provided by breast milk feeding. Overall, physiologic gut microbiota establishment and enrichment are facilitated by breast milk [69]. The maternal microbes excreted from the mammary gland, the contact to the skin of the breast, and the nutritional components of breast milk enable the maturation of immune functions and the establishment of a stable physiologic rich and diverse microbiome with a dominance of Bifidobacteria and Lactobacillus species but also presence of species of the genera Staphylococcus, Streptococcus, Propionibacterium, Bacteroides, Rothia, Enterococcusi, and Pseudomonas [99, 123-129]. But also strictly anaerobic gut commensals from the Clostridiaceae including Blautia, Clostridium, Collinsella and Veillonella species were detected in breast milk together with Coprococcus, Faecalibacterium, and Roseburia species, which were simultaneously isolated from the mothers' breast milk and stool. This allows the conclusion that additionally to the skin-gut axis a maternal gut-breast microbiome axis exists and that the infants' gut microbiome is shaped by the maternal gut microbiome [128, 130, 131]. Gut microbiota composition after preterm birth differs from that of mothers who delivered at term with a shift from Bifidobacterium to Enterococcus species. It is impacted by perinatal maternal antibiotic therapy with a decrease in Lactobacillus, Bifidobacterium, Staphylococcus, and Eubacterium species [132]. Formula fed infants display a further reduced microbial diversity and the dominance of Enterobacteriaceae, Coriobacteriaceae, and Bacteroides $[95,126]$. In preterm infants at high risk of gut microbial dysbiosis, probiotic therapy with the bacterial commensals identified in the previously mentioned studies proved overall efficient to reduce the incidence of necrotizing enterocolitis, sepsis, and death. However, the optimal strain or formula and the duration of application await further exploration $[73,74]$. Lactoferrin, a protein of the transferrin family with broad antimicrobial action, stands for the steep rising gain of knowledge about the gut microbiota shaping functions of breast milk. Its recombinant application does not only reduce the risk for device associated infections but modulates the fecal microbiome towards the physiologic situation [133]. In contrast to these medical therapeutic interventions, skin-to-skin care is an easy to apply clinical technique to shape the infants' microbiome. Its consistent provision shapes the oral microbiome of the preterm infant and helps to accelerate its maturation [134].

\section{Concluding Remarks}

The available data convincingly support the hypothesis that the pre- and postnatal microbiome contributes to premature delivery and to the acute sequelae in the preterm infant. Despite the tremendous scientific progress, we have just scratched the surface to understand the consequences of aberrant microbiota and their dynamic changes to disease initiation and progression. The current data convincingly highlight their impact on nosocomial infection and NEC, which constitute not only a tremendous disease burden to the preterm infant but more importantly entail life-long consequences and considerable lethality. Nonetheless, for most of the acute complications and short-term sequelae including pulmonary and cerebral problems a clear causerelationship is still missing. It remains to be determined whether pathogenic microbiota also account for the distortion of long-term somatic and psychomotor development in preterm infants which did not suffer from severe acute complications like infection or cerebral hemorrhage. 
Therefore, comprehensive and long-term oriented research efforts are urgently needed to cover these important and clinically highly relevant aspects. A comprehensive and mechanistic understanding of the connection between microbial dysbiosis and disease initiation and progression will help to develop new therapeutic concepts aiming to control and restore physiologic microbial structures. Further important topics of research are to gain detailed knowledge on microbial structures and how to avoid of sample contamination and to enable the comparability of studies with respect to techniques and sample preparation [135]. It remains an open question how our lifestyle habits and the genetic background impact the microbiome of the pregnant woman and the frequency of preterm born infants.

The successful implementation of postnatal probiotic therapy and further clinical guidelines raises hopes to reduce the maternal and fetal disease burden in the near future and to come to a targeted or even personalized medicine. Next steps can be derived from the observational studies and should include (1) the design of point-of-care techniques to determine microbial structures onsite and in real time to immediately identify the mother and infant at risk, (2) evaluation of the benefits of personalized medicine strategies of vaginal fluid or feces transplantation to the fetus and newborn, (3) the development of new strategies to detect bacterial infection with high prediction accuracy to avoid unnecessary and prolonged antibiotic therapy and subsequent microbial dysbiosis, and (4) to test more potent alternatives to current classical probiotics including mixtures of different bacterial strains and bacterial metabolites. Each of these areas poses tremendous challenges and opportunities to finally reduce the rates of prematurity and of the associated morbidities. Opening and reaching these new frontiers in perinatal science offer the opportunity to come closer to efficient prevention of preterm birth, which poses an ever greater global burden and challenge.

\section{Disclosure}

Birte Staude and Frank Oehmke both share first authorship.

\section{Conflicts of Interest}

The authors declare that there are no conflicts of interest regarding the publication of this paper.

\section{Authors' Contributions}

Birte Staude, Frank Oehmke, Tina Lauer, and Harald Ehrhardt drafted the manuscript and designed the figures. Judith Behnke, Wolfgang Göpel, Michael Schloter, Holger Schulz, and Susanne Krauss-Etschmann provided valuable intellectual input and edited and revised the manuscript. All authors read and approved the final version of the manuscript.

\section{Acknowledgments}

The authors highly appreciate realization of figure layout by CE marketing \& PR services, Germany. This work was supported by research grants from the German Research Foundation (KFO 309), von Behring Röntgen Stiftung (630009 and 65-0019), and the Leibniz Competition 2016 "Lung Microbiota the Interface between Airway Epithelium and the Environment."

\section{References}

[1] C. A. Lozupone, J. I. Stombaugh, J. I. Gordon, J. K. Jansson, and R. Knight, "Diversity, stability and resilience of the human gut microbiota," Nature, vol. 489, no. 7415, pp. 220-230, 2012.

[2] C. A. Combs, M. Gravett, T. J. Garite et al., "Amniotic fluid infection, inflammation, and colonization in preterm labor with intact membranes," American Journal of Obstetrics \& Gynecology, vol. 210, no. 2, pp. 125.e1-125.e15, 2014.

[3] R. Satokari, T. Gronroos, K. Laitinen, S. Salminen, and E. Isolauri, "Bifidobacterium and Lactobacillus DNA in the human placenta," Letters in Applied Microbiology, vol. 48, no. 1, pp. 812, 2009.

[4] J. H. Steel, S. Malatos, N. Kennea et al., "Bacteria and inflammatory cells in fetal membranes do not always cause preterm labor," Pediatric Research, vol. 57, no. 3, pp. 404-411, 2005.

[5] M. G. De Agüero, S. C. Ganal-Vonarburg, and T. Fuhrer, "The maternal microbiota drives early postnatal innate immune development," Science, vol. 351, no. 6279, pp. 1296-1302, 2016.

[6] M. C. Collado, S. Rautava, J. Aakko, E. Isolauri, and S. Salminen, "Human gut colonisation may be initiated in utero by distinct microbial communities in the placenta and amniotic fluid," Scientific Reports, vol. 6, 2016.

[7] K. Aagaard, J. Ma, K. M. Antony, R. Ganu, J. Petrosino, and J. Versalovic, "The placenta harbors a unique microbiome," Science Translational Medicine, vol. 6, no. 237, Article ID 237ra65, 2014.

[8] M. E. Perez-Muñoz, M.-C. Arrieta, A. E. Ramer-Tait, and J. Walter, "A critical assessment of the "sterile womb" and "in utero colonization" hypotheses: Implications for research on the pioneer infant microbiome," Microbiome, vol. 5, no. 1, article no. 48, 2017.

[9] A. C. Freitas, B. Chaban, A. Bocking et al., "The vaginal microbiome of pregnant women is less rich and diverse, with lower prevalence of Mollicutes, compared to non-pregnant women," Scientific Reports, vol. 7, no. 1, 2017.

[10] E. Avershina, S. Slangsvold, M. R. Simpson et al., "Diversity of vaginal microbiota increases by the time of labor onset," Scientific Reports, vol. 7, no. 1, 2017.

[11] R. Romero, S. S. Hassan, P. Gajer et al., "The composition and stability of the vaginal microbiota of normal pregnant women is different from that of non-pregnant women," Microbiome, vol. 2, no. 1, 2014

[12] K. Aagaard, K. Riehle, J. Ma et al., "A metagenomic approach to characterization of the vaginal microbiome signature in pregnancy," PLoS ONE, vol. 7, no. 6, 2012.

[13] D. B. DiGiulio, B. J. Callahan, P. J. McMurdie et al., “Temporal and spatial variation of the human microbiota during pregnancy," Proceedings of the National Acadamy of Sciences of the United States of America, vol. 112, no. 35, pp. 11060-11065, 2015.

[14] J. Ravel, P. Gajer, Z. Abdo et al., "Vaginal microbiome of reproductive-age women," Proceedings of the National Acadamy of Sciences of the United States of America, vol. 108, no. 1, pp. 4680-4687, 2011. 
[15] The Human Microbiome Project Consortium, "Structure, function and diversity of the healthy human microbiome," Nature, vol. 486, pp. 207-214, 2012.

[16] R. W. Hyman, M. Fukushima, H. Jiang et al., "Diversity of the vaginal microbiome correlates with preterm birth," Reproductive Sciences, vol. 21, no. 1, pp. 32-40, 2014.

[17] R. Vemuri, R. Gundamaraju, M. D. Shastri et al., "Gut microbial changes, interactions, and their implications on human lifecycle: an ageing perspective," BioMed Research International, vol. 2018, 13 pages, 2018.

[18] M. G. Dominguez-Bello, E. K. Costello, M. Contreras et al., "Delivery mode shapes the acquisition and structure of the initial microbiota across multiple body habitats in newborns," Proceedings of the National Acadamy of Sciences of the United States of America, vol. 107, no. 26, pp. 11971-11975, 2010.

[19] D. M. Chu, J. Ma, A. L. Prince, K. M. Antony, M. D. Seferovic, and K. M. Aagaard, "Maturation of the infant microbiome community structure and function across multiple body sites and in relation to mode of delivery," Nat Med, vol. 23, no. 3, pp. 314-326, 2017.

[20] J. Neu and J. Rushing, "Cesarean versus vaginal delivery: longterm infant outcomes and the hygiene hypothesis," Clinics in Perinatology, vol. 38, no. 2, pp. 321-331, 2011.

[21] Y. Zhou and F. Zhi, "Lower level of bacteroides in the gut microbiota is associated with inflammatory bowel disease: a meta-analysis," BioMed Research International, vol. 2016, 2016.

[22] K. E. Gregory, R. D. Laplante, G. Shan, D. V. Kumar, and M. Gregas, "Mode of birth influences preterm infant intestinal colonization with bacteroides over the early neonatal period," Advances in Neonatal Care, vol. 15, no. 6, pp. 386-393, 2015.

[23] C. J. Stewart, N. D. Embleton, E. Clements et al., "Cesarean or vaginal birth does not impact the longitudinal development of the gut microbiome in a cohort of exclusively preterm infants," Frontiers in Microbiology, vol. 8, 2017.

[24] R. Romero, S. K. Dey, and S. J. Fisher, "Preterm labor: one syndrome, many causes," Science, vol. 345 , no. 6198, pp. $760-$ 765, 2014.

[25] M. S. Rose, G. Pana, and S. Premji, "Prenatal maternal anxiety as a risk factor for preterm birth and the effects of heterogeneity on this relationship: a systematic review and meta-analysis," BioMed Research International, vol. 2016, 2016.

[26] A. T. N. Tita and W. W. Andrews, "Diagnosis and management of clinical chorioamnionitis," Clinics in Perinatology, vol. 37, no. 2, pp. 339-354, 2010.

[27] R. W. Redline, "Inflammatory responses in the placenta and umbilical cord," Seminars in Fetal and Neonatal Medicine, vol. 11, no. 5, pp. 296-301, 2006.

[28] D. Urushiyama, W. Suda, E. Ohnishi et al., "Microbiome profile of the amniotic fluid as a predictive biomarker of perinatal outcome," Scientific Reports, vol. 7, no. 1, 2017.

[29] J. Trowsdale and A. G. Betz, "Mother's little helpers: Mechanisms of maternal-fetal tolerance," Nature Immunology, vol. 7, no. 3, pp. 241-246, 2006.

[30] M. Azizia, J. Lloyd, M. Allen, N. Klein, and D. Peebles, "Immune status in very preterm neonates," Pediatrics, vol. 129, no. 4, pp. e967-e974, 2012.

[31] S. G. Kallapur, B. W. Kramer, C. L. Knox et al., "Chronic fetal exposure to Ureaplasma parvum suppresses innate immune responses in sheep," The Journal of Immunology, vol. 187, no. 5, pp. 2688-2695, 2011.
[32] K. M. Antony, J. Ma, K. B. Mitchell, D. A. Racusin, J. Versalovic, and K. Aagaard, "The preterm placental microbiome varies in association with excess maternal gestational weight gain," American Journal of Obstetrics \& Gynecology, vol. 212, no. 5, pp. 653-653.e16, 2015.

[33] R. M. Doyle, D. G. Alber, H. E. Jones et al., “Term and preterm labour are associated with distinct microbial community structures in placental membranes which are independent of mode of delivery," Placenta, vol. 35, no. 12, pp. 1099-1101, 2014.

[34] A. L. Prince, J. Ma, P. S. Kannan et al., "The placental membrane microbiome is altered among subjects with spontaneous preterm birth with and without chorioamnionitis," American Journal of Obstetrics \& Gynecology, vol. 214, no. 5, pp. 627627e16, 2016.

[35] D. B. DiGiulio, R. Romero, H. P. Amogan et al., "Microbial prevalence, diversity and abundance in amniotic fluid during preterm labor: a molecular and culture-based investigation," PLoS ONE, vol. 3, no. 8, Article ID e3056, 2008.

[36] D. J. Desa and C. L. Trevenen, "Intrauterine infections with group B beta-haemolytic streptococci," British Journal of Obstetrics and Gynaecology, vol. 91, no. 3, pp. 237-239, 1984.

[37] P. A. Shurin, S. Alpert, B. Rosner et al., "Chorioamnionitis and colonization of the newborn infant with genital mycoplasmas," The New England Journal of Medicine, vol. 293, no. 1, pp. 5-8, 1975.

[38] R. B. Kundsin, S. G. Driscoll, R. R. Monson, C. Yeh, S. A. Biano, and W. D. Cochran, "Association of ureaplasma urealyticum in the placenta with perinatal morbidity and mortality," The New England Journal of Medicine, vol. 310, no. 15, pp. 941-945, 1984.

[39] M. S. Payne and S. Bayatibojakhi, "Exploring preterm birth as a polymicrobial disease: An overview of the uterine microbiome," Frontiers in Immunology, vol. 5, 2014.

[40] R. Romero, S. S. Hassan, P. Gajer et al., "The vaginal microbiota of pregnant women who subsequently have spontaneous preterm labor and delivery and those with a normal delivery at term," Microbiome, vol. 2, no. 1, article 18, 2014.

[41] S. L. Hillier, R. P. Nugent, D. A. Eschenbach et al., "Association between bacterial vaginosis and preterm delivery of a low-birthweight infant," The New England Journal of Medicine, vol. 333, no. 26, pp. 1737-1742, 1995.

[42] S. S. Seo, S. Arokiyaraj, M. K. Kim et al., "High prevalence of leptotrichia amnionii, atopobium vaginae, sneathia sanguinegens, and factor 1 microbes and association of spontaneous abortion among Korean women," BioMed Research International, vol. 2017, 2017.

[43] W. W. Andrews, R. L. Goldenberg, B. Mercer et al., “The preterm prediction study: association of second-trimester genitourinary chlamydia infection with subsequent spontaneous preterm birth," American Journal of Obstetrics \& Gynecology, vol. 183, no. 3, pp. 662-668, 2000.

[44] M. J. Stout, Y. Zhou, K. M. Wylie, P. I. Tarr, G. A. Macones, and M. G. Tuuli, "Early pregnancy vaginal microbiome trends and preterm birth," American Journal of Obstetrics \& Gynecology, vol. 217, no. 3, pp. 356-356.e18, 2017.

[45] S. Filardo, M. Di Pietro, M. G. Porpora et al., "Diversity of cervical microbiota in asymptomatic chlamydia trachomatis genital infection: A pilot study," Frontiers in Cellular and Infection Microbiology, vol. 7, 2017.

[46] M. Kacerovsky, F. Vrbacky, R. Kutova et al., "Cervical microbiota in women with preterm prelabor rupture of membranes," PLoS ONE, vol. 10, no. 5, 2015. 
[47] G. Rizzatti, L. R. Lopetuso, G. Gibiino, C. Binda, and A. Gasbarrini, "Proteobacteria: A common factor in human diseases," BioMed Research International, vol. 2017, 2017.

[48] K. L. Connor, C. Chehoud, L. Chan, P. DiStefano, T. DeSantis, and S. J. Lye, "Maternal diet shapes the gut microbiome, impacting immune status in pregnancy," in Reproductive Sciences, vol. 21, Thousand Oaks, Calif, USA, 2014.

[49] A. Shiozaki, S. Yoneda, N. Yoneda et al., "Intestinal microbiota is different in women with preterm birth: Results from terminal restriction fragment length polymorphism analysis," PLoS ONE, vol. 9, no. 11, 2014.

[50] O. Koren, J. K. Goodrich, T. C. Cullender et al., "Host remodeling of the gut microbiome and metabolic changes during pregnancy," Cell, vol. 150, no. 3, pp. 470-480, 2012.

[51] C. Dahl, M. Stanislawski, N. Iszatt et al., "Gut microbiome of mothers delivering prematurely shows reduced diversity and lower relative abundance of Bifidobacterium and Streptococcus," PLoS ONE, vol. 12, no. 10, 2017.

[52] A. N. Ardissone, D. M. De La Cruz, A. G. Davis-Richardson et al., "Meconium microbiome analysis identifies bacteria correlated with premature birth," PLoS ONE, vol. 9, no. 3, 2014.

[53] L. Moles, M. Gómez, H. Heilig et al., "Bacterial diversity in meconium of preterm neonates and evolution of their fecal microbiota during the first month of life," PLoS ONE, vol. 8, no. 6, Article ID e66986, 2013.

[54] G. Bröms, F. Granath, M. Linder, O. Stephansson, M. Elmberg, and $\mathrm{H}$. Kieler, "Birth outcomes in women with inflammatory bowel disease: effects of disease activity and drug exposure," Inflammatory Bowel Diseases, vol. 20, no. 6, pp. 1091-1098, 2014.

[55] M. Gantert, J. V. Been, A. W. D. Gavilanes, Y. Garnier, L. J. I. Zimmermann, and B. W. Kramer, "Chorioamnionitis: A multiorgan disease of the fetus," Journal of Perinatology, vol. 30, no. 1, pp. S21-S30, 2010.

[56] T. Reicherzer, S. Häffner, T. Shahzad et al., "Activation of the NF- $\kappa \mathrm{B}$ pathway alters the phenotype of MSCs in the tracheal aspirates of preterm infants with severe BPD," American Journal of Physiology-Lung Cellular and Molecular Physiology, vol. 315, no. 1, pp. L87-L101, 2018.

[57] H. Ehrhardt, T. Pritzke, P. Oak et al., "Absence of TNF- $\alpha$ enhances inflammatory response in the newborn lung undergoing mechanical ventilation," American Journal of PhysiologyLung Cellular and Molecular Physiology, vol. 310, no. 10, pp. L909-L918, 2016.

[58] T. Shahzad, S. Radajewski, C. Chao, S. Bellusci, and H. Ehrhardt, "Pathogenesis of bronchopulmonary dysplasia: when inflammation meets organ development," Molecular and Cellular Pediatrics, vol. 3, no. 1, 2016.

[59] J. Gronbach, T. Shahzad, S. Radajewski et al., "The potentials and caveats of mesenchymal stromal cell-based therapies in the preterm infant," Stem Cells International, vol. 2018, Article ID 9652897, 15 pages, 2018.

[60] P. M. Mourani, J. K. Harris, M. K. Sontag, C. E. Robertson, and S. H. Abman, "Molecular identification of bacteria in tracheal aspirate fluid from mechanically ventilated preterm infants," PLoS ONE, vol. 6, no. 10, 2011.

[61] K. C. Young, T. del Moral, N. Claure, S. Vanbuskirk, and E. Bancalari, "The association between early tracheal colonization and bronchopulmonary dysplasia," Journal of Perinatology, vol. 25, no. 6, pp. 403-407, 2005.

[62] J. Lowe, W. J. Watkins, M. O. Edwards et al., "Association between pulmonary ureaplasma colonization and bronchopulmonary dysplasia in preterm infants: Updated systematic review and meta-analysis," The Pediatric Infectious Disease Journal, vol. 33, no. 7, pp. 697-702, 2014.

[63] L. Hartling, Y. Liang, and T. Lacaze-Masmonteil, "Chorioamnionitis as a risk factor for bronchopulmonary dysplasia: A systematic review and meta-analysis," ADC - Fetal and Neonatal Edition, vol. 97, no. 1, pp. F8-F17, 2012.

[64] B. D. Wagner, M. K. Sontag, J. K. Harris et al., "Prenatal complications are associated with the postnatal airway host response and microbiota in intubated preterm infants," The journal of maternal-fetal \& neonatal medicine: the official journal of the European Association of Perinatal Medicine, the Federation of Asia and Oceania Perinatal Societies, the International Society of Perinatal Obstetricians, pp. 1-8, 2017.

[65] P. Lohmann, R. A. Luna, E. B. Hollister et al., "The airway microbiome of intubated premature infants: Characteristics and changes that predict the development of bronchopulmonary dysplasia," Pediatric Research, vol. 76, no. 3, pp. 294-301, 2014.

[66] B. D. Wagner, M. K. Sontag, J. K. Harris et al., "Airway microbial community turnover differs by BPD severity in ventilated preterm infants," PLoS ONE, vol. 12, no. 1, 2017.

[67] C. V. Lal, N. Olave, C. Travers et al., "Exosomal microRNA predicts and protects against severe bronchopulmonary dysplasia in extremely premature infants," JCI Insight, vol. 3, no. 5, 2018.

[68] C. V. Lal, C. Travers, Z. H. Aghai et al., "The airway microbiome at birth," Scientific Reports, vol. 6, 2016.

[69] K. E. Gregory, B. S. Samuel, P. Houghteling et al., "Influence of maternal breast milk ingestion on acquisition of the intestinal microbiome in preterm infants," Microbiome, vol. 4, no. 1, p. 68, 2016.

[70] E. C. Claud and W. A. Walker, "Hypothesis: inappropriate colonization of the premature intestine can cause neonatal necrotizing enterocolitis," The FASEB Journal, vol. 15, no. 8, pp. 1398-1403, 2001.

[71] M. Good, C. P. Sodhi, C. E. Egan et al., "Breast milk protects against the development of necrotizing enterocolitis through inhibition of Toll-like receptor 4 in the intestinal epithelium via activation of the epidermal growth factor receptor," Mucosal Immunology, vol. 8, no. 5, pp. 1166-1179, 2015.

[72] C. Greenwood, A. L. Morrow, and A. J. Lagomarcino, "Early empiric antibiotic use in preterm infants is associated with lower bacterial diversity and higher relative abundance of Enterobacter," Journal of Pediatrics, vol. 165, no. 1, pp. 23-29, 2014.

[73] E. Dermyshi, Y. Wang, C. Yan et al., "The "golden Age" of Probiotics: a systematic review and meta-analysis of randomized and observational studies in preterm infants," Neonatology, vol. 112, no. 1, pp. 9-23, 2017.

[74] K. Alfaleh, J. Anabrees, D. Bassler, and T. Al-Kharfi, "Probiotics for prevention of necrotizing enterocolitis in preterm infants.", Cochrane Database of Systematic Reviews (Online), vol. 3, p. CD005496, 2011.

[75] F. Aujoulat, L. Roudière, J.-C. Picaud et al., “Temporal dynamics of the very premature infant gut dominant microbiota," $B M C$ Microbiology, vol. 14, no. 1, 2014.

[76] L. Ferraris, M. J. Butel, F. Campeotto, M. Vodovar, J. C. Rozé, and J. Aires, "Clostridia in premature neonates' gut: Incidence, antibiotic susceptibility, and perinatal determinants influencing colonization," PLoS ONE, vol. 7, no. 1, 2012.

[77] P. S. La Rosa, B. B. Warner, Y. Zhou et al., "Patterned progression of bacterial populations in the premature infant gut," Proceedings of the National Acadamy of Sciences of the United States of America, vol. 111, no. 34, pp. 12522-12527, 2014. 
[78] B. B. Warner, E. Deych, Y. Zhou et al., "Gut bacteria dysbiosis and necrotising enterocolitis in very low birthweight infants: A prospective case-control study," The Lancet, vol. 387, no. 10031, pp. 1928-1936, 2016.

[79] S. Arboleya, B. Sánchez, C. Milani et al., "Intestinal microbiota development in preterm neonates and effect of perinatal antibiotics," Journal of Pediatrics, vol. 166, no. 3, pp. 538-544, 2015.

[80] K. Patel, K. Konduru, A. K. Patra, D. S. Chandel, and P. Panigrahi, "Trends and determinants of gastric bacterial colonization of preterm neonates in a NICU setting," PLOS ONE, vol. 10, no. 7, 2015.

[81] U. Parm, T. Metsvaht, E. Sepp et al., "Risk factors associated with gut and nasopharyngeal colonization by common Gramnegative species and yeasts in neonatal intensive care units patients," Early Human Development, vol. 87, no. 6, pp. 391-399, 2011.

[82] J.-C. Rozé, P.-Y. Ancel, P. Lepage et al., "Nutritional strategies and gut microbiota composition as risk factors for necrotizing enterocolitis in very-preterm infants," American Journal of Clinical Nutrition, vol. 106, no. 3, pp. 821-830, 2017.

[83] Y. Wang, J. D. Hoenig, K. J. Malin et al., "16S rRNA genebased analysis of fecal microbiota from preterm infants with and without necrotizing enterocolitis," The ISME Journal, vol. 3, no. 8, pp. 944-954, 2009.

[84] V. E. McMurtry, R. W. Gupta, L. Tran et al., "Bacterial diversity and Clostridia abundance decrease with increasing severity of necrotizing enterocolitis," Microbiome, vol. 3, no. 1, 2015.

[85] M. Pammi, J. Cope, P. I. Tarr et al., "Intestinal dysbiosis in preterm infants preceding necrotizing enterocolitis: A systematic review and meta-analysis," Microbiome, vol. 5, no. 1, 2017.

[86] A. Hilgendorff, A. Windhorst, M. Klein et al., "Gene expression profiling at birth characterizing the preterm infant with early onset infection," Journal of Molecular Medicine, vol. 95, no. 2, pp. 169-180, 2017.

[87] J. Pagel, A. Hartz, J. Figge et al., "Regulatory T cell frequencies are increased in preterm infants with clinical early-onset sepsis," Clinical \& Experimental Immunology, vol. 185, no. 2, pp. 219227, 2016.

[88] A. Birle, C. T. Nebe, S. Hill, K. Hartmann, J. Poeschl, and L. Koch, "Neutrophil chemotaxis in cord blood of term and preterm neonates is reduced in preterm neonates and influenced by the mode of delivery and anaesthesia," PLOS ONE, vol. 10, no. 4, 2015.

[89] A. L. Silveira-Lessa, C. Quinello, L. Lima et al., "TLR expression, phagocytosis and oxidative burst in healthy and septic newborns in response to Gram-negative and Gram-positive rods," Human Immunology, vol. 77, no. 10, pp. 972-980, 2016.

[90] E. De Jong, T. Strunk, D. Burgner, P. M. Lavoie, and A. Currie, "The phenotype and function of preterm infant monocytes: Implications for susceptibility to infection," Journal of Leukocyte Biology, vol. 102, no. 3, pp. 645-656, 2017.

[91] F. Behnia, S. Sheller, and R. Menon, "Mechanistic differences leading to infectious and sterile inflammation," American Journal of Reproductive Immunology, vol. 75, no. 5, pp. 505-518, 2016.

[92] B. Tröger, T. Müller, K. Faust et al., "Intrauterine growth restriction and the innate immune system in preterm infants of $\leq 32$ weeks gestation," Neonatology, vol. 103, no. 3, pp. 199-204, 2013.

[93] H. Suzuki-Kakisaka, J. Sugimoto, M. Tetarbe, A. M. Romani, C. M. Ramirez Kitchen, and H. B. Bernstein, "Magnesium sulfate increases intracellular magnesium reducing inflammatory cytokine release in neonates," American Journal of Reproductive Immunology, vol. 70, no. 3, pp. 213-220, 2013.

[94] E. Kuypers, J. J. P. Collins, B. W. Kramer et al., "Intra-amniotic LPS and antenatal betamethasone: Inflammation and maturation in preterm lamb lungs," American Journal of PhysiologyLung Cellular and Molecular Physiology, vol. 302, no. 4, pp. L380-L389, 2012.

[95] X. Cong, M. Judge, W. Xu et al., "Influence of feeding type on gut microbiome development in hospitalized preterm infants," Nursing Research, vol. 66, no. 2, pp. 123-133, 2017.

[96] M. Pammi, J. L. O’Brien, N. J. Ajami, M. C. Wong, J. Versalovic, and J. F. Petrosino, "Development of the cutaneous microbiome in the preterm infant: A prospective longitudinal study," PLoS ONE, vol. 12, no. 4, 2017.

[97] M. A. Carl, I. M. Ndao, A. C. Springman et al., "Sepsis from the gut: The enteric habitat of bacteria that cause late-onset neonatal bloodstream infections," Clinical Infectious Diseases, vol. 58, no. 9, pp. 1211-1218, 2014.

[98] A. G. Shaw, K. Sim, P. Randell et al., "Late-Onset bloodstream infection and perturbed maturation of the gastrointestinal microbiota in premature infants," PLoS ONE, vol. 10, no. 7, 2015.

[99] C. J. Hill, D. B. Lynch, K. Murphy et al., "Evolution of gut microbiota composition from birth to 24 weeks in the INFANTMET Cohort," Microbiome, vol. 5, no. 1, 2017.

[100] J. C. Madan, R. C. Salari, D. Saxena et al., "Gut microbial colonisation in premature neonates predicts neonatal sepsis," ADC - Fetal and Neonatal Edition, vol. 97, no. 6, pp. F456-F462, 2012.

[101] M. K. Gibson, B. Wang, S. Ahmadi et al., "Developmental dynamics of the preterm infant gut microbiota and antibiotic resistome," Nature Microbiology, vol. 1, p. 16024, 2016.

[102] L. Corvaglia, G. Tonti, S. Martini et al., "Influence of intrapartum antibiotic prophylaxis for group B streptococcus on gut microbiota in the first month of life," Journal of Pediatric Gastroenterology and Nutrition, vol. 62, no. 2, pp. 304-308, 2016.

[103] L. Keski-Nisula, H.-R. Kyynäräinen, U. Kärkkäinen, J. Karhukorpi, S. Heinonen, and J. Pekkanen, "Maternal intrapartum antibiotics and decreased vertical transmission of Lactobacillus to neonates during birth," Acta Paediatrica, vol. 102, no. 5, pp. 480-485, 2013.

[104] C. Meng, J. G. Bäuml, M. Daamen et al., "Extensive and interrelated subcortical white and gray matter alterations in preterm-born adults," Brain Structure \& Function, vol. 221, no. 4, pp. 2109-2121, 2016.

[105] O. Kapellou, S. J. Counsell, N. Kennea et al., "Abnormal cortical development after premature birth shown by altered allometric scaling of brain growth," PLoS Medicine, vol. 3, no. 8, pp. 13821390, 2006.

[106] S. M. Collins, M. Surette, and P. Bercik, "The interplay between the intestinal microbiota and the brain," Nature Reviews Microbiology, vol. 10, no. 11, pp. 735-742, 2012.

[107] N. Sudo, Y. Chida, Y. Aiba et al., "Postnatal microbial colonization programs the hypothalamic-pituitary-adrenal system for stress response in mice," The Journal of Physiology, vol. 558, no. 1, pp. 263-275, 2004.

[108] B. L. Bonaz and C. N. Bernstein, "Brain-gut interactions in inflammatory bowel disease," Gastroenterology, vol. 144, no. 1, pp. 36-49, 2013.

[109] T. G. Dinan and J. F. Cryan, "Regulation of the stress response by the gut microbiota: Implications for psychoneuroendocrinology," Psychoneuroendocrinology, vol. 37, no. 9, pp. 1369-1378, 2012. 
[110] A. L. Carlson, K. Xia, M. A. Azcarate-Peril et al., "Infant gut microbiome associated with cognitive development," Biological Psychiatry, vol. 83, no. 2, pp. 148-159, 2018.

[111] R. J. Van Lieshout, M. H. Boyle, L. Favotto et al., "Impact of extremely low-birth-weight status on risk and resilience for depression and anxiety in adulthood," Journal of Child Psychology and Psychiatry, vol. 59, no. 5, pp. 596-603, 2018.

[112] R. M. Joseph, S. J. Korzeniewski, E. N. Allred et al., "Extremely low gestational age and very low birthweight for gestational age are risk factors for autism spectrum disorder in a large cohort study of 10-year-old children born at 23-27 weeks' gestation," American Journal of Obstetrics and Gynecology, vol. 216, no. 3, 2017.

[113] A. Posod, I. O. Komazec, U. P. Peglow, D. Meraner, E. Griesmaier, and U. Kiechl-Kohlendorfer, "Former very preterm infants show alterations in thyroid function at a preschool age," BioMed Research International, vol. 2017, 2017.

[114] J. P. Van Den Berg, E. A. M. Westerbeek, T. Bröring-Starre, J. Garssen, and R. M. Van Elburg, "Neurodevelopment of preterm infants at 24 months after neonatal supplementation of a prebiotic mix: A randomized trial," Journal of Pediatric Gastroenterology and Nutrition, vol. 63, no. 2, pp. 270-276, 2016.

[115] S. Tochitani, T. Ikeno, T. Ito, A. Sakurai, T. Yamauchi, and H. Matsuzaki, "Administration of non-Absorbable antibiotics to pregnant mice to perturb the maternal gut microbiota is associated with alterations in offspring behavior," PLOS ONE, vol. 11, no. 1, 2016.

[116] J. B. Adams, L. J. Johansen, L. D. Powell, D. Quig, and R. A. Rubin, "Gastrointestinal flora and gastrointestinal status in children with autism-comparisons to typical children and correlation with autism severity," BMC Gastroenterology, vol. 11, article 22, 2011.

[117] R. D. Heijtz, S. Wang, F. Anuar et al., "Normal gut microbiota modulates brain development and behavior," Proceedings of the National Acadamy of Sciences of the United States of America, vol. 108, no. 7, pp. 3047-3052, 2011.

[118] J. D. Galley and M. T. Bailey, "Impact of stressor exposure on the interplay between commensal microbiota and host inflammation," Gut Microbes, vol. 5, no. 3, 2014.

[119] M. T. Bailey, S. E. Dowd, J. D. Galley, A. R. Hufnagle, R. G. Allen, and M. Lyte, "Exposure to a social stressor alters the structure of the intestinal microbiota: implications for stressor-induced immunomodulation," Brain, Behavior, and Immunity, vol. 25, no. 3, pp. 397-407, 2011.

[120] E. Y. Hsiao, S. W. McBride, S. Hsien et al., "Microbiota modulate behavioral and physiological abnormalities associated with neurodevelopmental disorders," Cell, vol. 155, no. 7, pp. 14511463, 2013.

[121] X. Cong, J. Wu, D. Vittner et al., "The impact of cumulative pain/stress on neurobehavioral development of preterm infants in the NICU," Early Human Development, vol. 108, pp. 9-16, 2017.

[122] D. Erny, A. L. H. De Angelis, D. Jaitin et al., "Host microbiota constantly control maturation and function of microglia in the CNS," Nature Neuroscience, vol. 18, no. 7, pp. 965-977, 2015.

[123] T. Jost, C. Lacroix, C. Braegger, and C. Chassard, "Assessment of bacterial diversity in breast milk using culture-dependent and culture-independent approaches," British Journal of Nutrition, vol. 110, no. 7, pp. 1253-1262, 2013.

[124] R. Cabrera-Rubio, M. C. Collado, K. Laitinen, S. Salminen, E. Isolauri, and A. Mira, "The human milk microbiome changes over lactation and is shaped by maternal weight and mode of delivery," American Journal of Clinical Nutrition, vol. 96, no. 3, pp. 544-551, 2012.

[125] P. S. Pannaraj, F. Li, C. Cerini et al., "Association between breast milk bacterial communities and establishment and development of the infant gut microbiome," JAMA Pediatrics, vol. 171, no. 7, pp. 647-654, 2017.

[126] G. Solís, C. G. de los Reyes-Gavilan, N. Fernández, A. Margolles, and M. Gueimonde, "Establishment and development of lactic acid bacteria and bifidobacteria microbiota in breast-milk and the infant gut," Anaerobe, vol. 16, no. 3, pp. 307-310, 2010.

[127] M. P. Heikkilä and P. E. J. Saris, "Inhibition of Staphylococcus aureus by the commensal bacteria of human milk," Journal of Applied Microbiology, vol. 95, no. 3, pp. 471-478, 2003.

[128] K. M. Hunt, J. A. Foster, L. J. Forney et al., "Characterization of the diversity and temporal stability of bacterial communities in human milk," PLoS ONE, vol. 6, no. 6, 2011.

[129] T. L. Ward, S. Hosid, I. Ioshikhes, and I. Altosaar, "Human milk metagenome: A functional capacity analysis," BMC Microbiology, vol. 13, no. 1, article no. 116, 2013.

[130] V. Martín, A. Maldonado-Barragán, and L. Moles, "Sharing of bacterial strains between breast milk and infant feces," Journal of Human Lactation, vol. 28, no. 1, pp. 36-44, 2012.

[131] T. Jost, C. Lacroix, C. P. Braegger, F. Rochat, and C. Chassard, "Vertical mother-neonate transfer of maternal gut bacteria via breastfeeding," Environmental Microbiology, vol. 16, no. 9, pp. 2891-2904, 2014.

[132] P. Khodayar-Pardo, L. Mira-Pascual, M. C. Collado, and C. Martínez-Costa, "Impact of lactation stage, gestational age and mode of delivery on breast milk microbiota," Journal of Perinatology, vol. 34, no. 8, pp. 599-605, 2014.

[133] M. P. Sherman, J. Sherman, R. Arcinue, and V. Niklas, "Randomized control trial of human recombinant lactoferrin: a substudy reveals effects on the fecal microbiome of very low birth weight infants," Journal of Pediatrics, vol. 173, pp. S37-S42, 2016.

[134] K. D. Hendricks-Muñoz, J. Xu, H. I. Parikh et al., "Skin-toskin care and the development of the preterm infant oral microbiome," American Journal of Perinatology, vol. 32, no. 13, pp. 1205-1216, 2015.

[135] G. R. Young, D. L. Smith, N. D. Embleton et al., "Reducing viability bias in analysis of gut microbiota in preterm infants at risk of NEC and sepsis," Frontiers in Cellular and Infection Microbiology, vol. 7, 2017. 


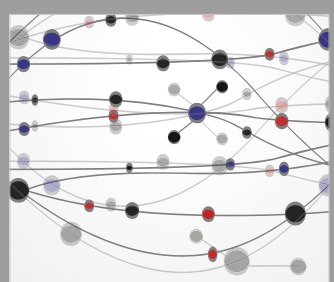

The Scientific World Journal
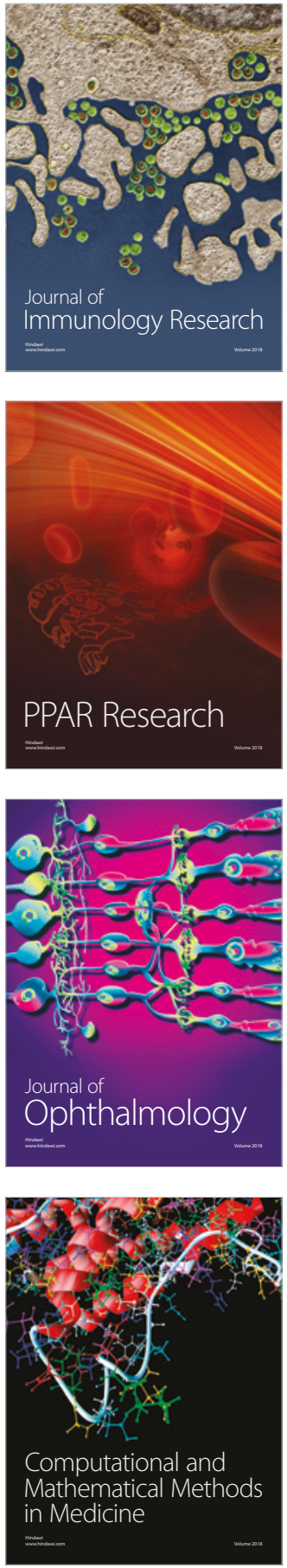

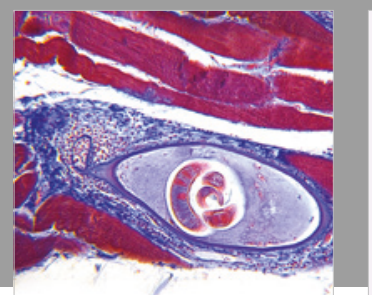

Gastroenterology Research and Practice

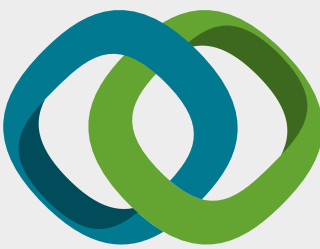

\section{Hindawi}

Submit your manuscripts at

www.hindawi.com
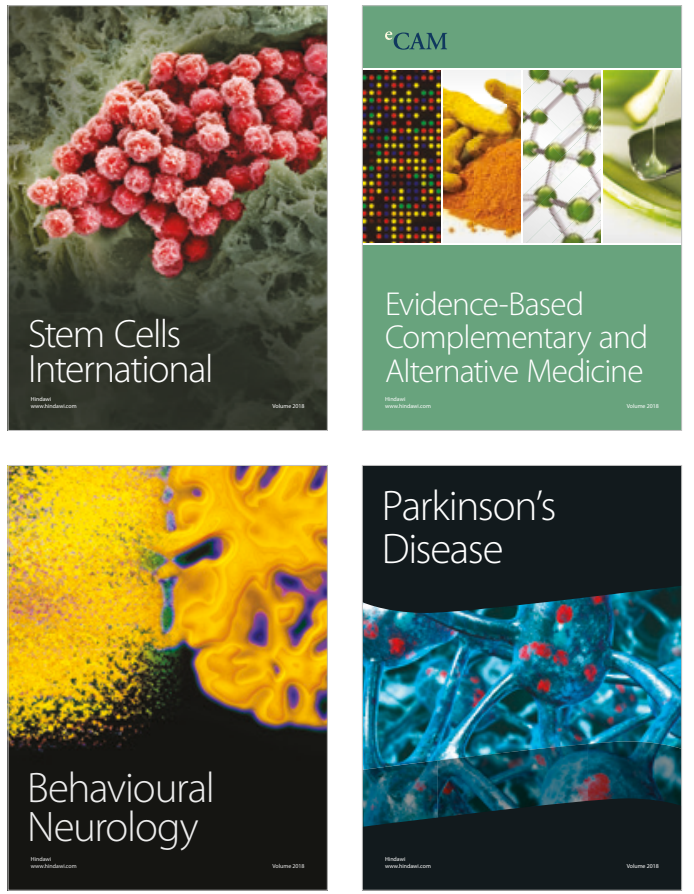

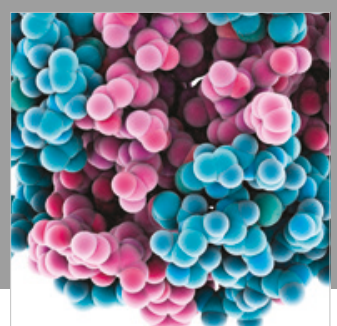

ournal of

Diabetes Research

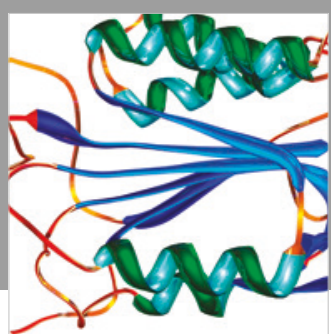

Disease Markers
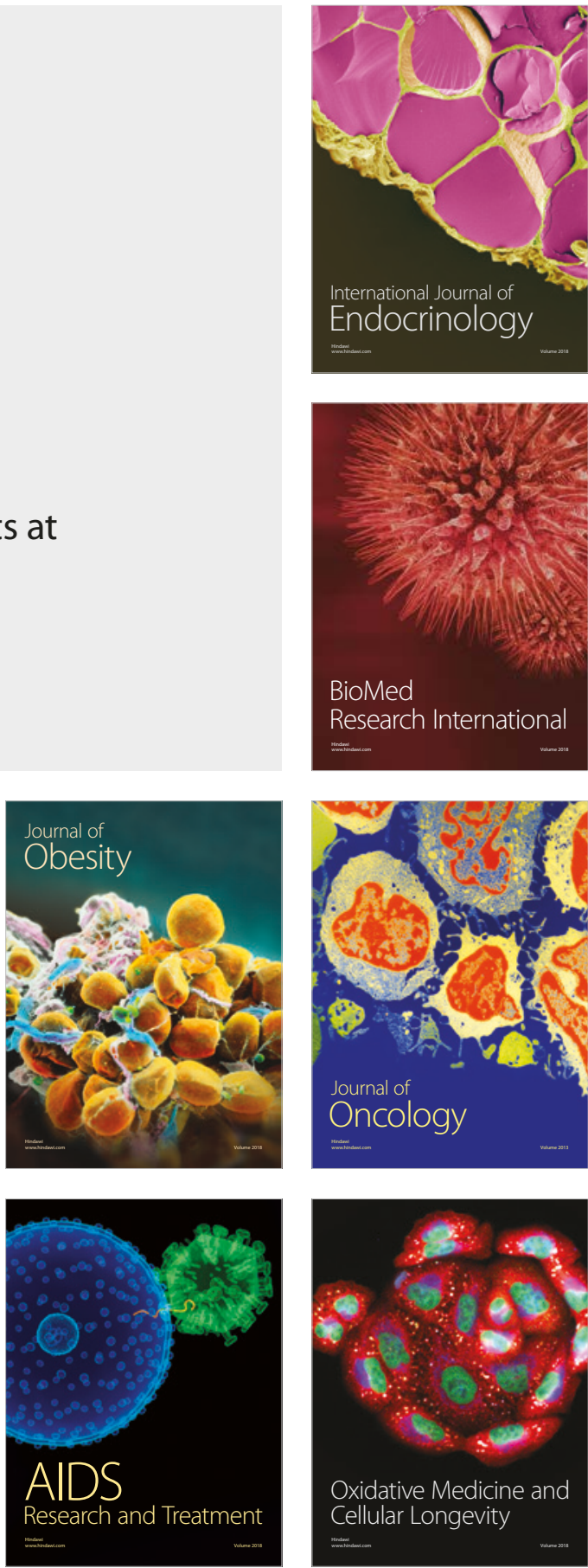